\title{
Injury surveillance in a rugby tournament
}

\author{
M Wekesa, J M Asembo, W W S Njororai
}

\begin{abstract}
Objective-To investigate injuries in international rugby football.

Methods-All injuries that led to temporary stoppage of the game or to the substitution of a player during the Rugby World Cup prequalifying tournament were recorded. Six matches were played, involving the Arabian Gulf, Kenya, Namibia, and Zimbabwe.

Results -47 injuries were recorded, giving an injury rate of eight per match. The number of injuries decreased from $38 \cdot 3 \%$ in the first matches to $23.4 \%$ in the final ones. The most serious injury was a concussion and the majority of the injuries affected soft tissues. Anatomically, the lower limbs suffered most injuries $(46.8 \%)$, followed by the head $(21 \cdot 3 \%)$, trunk $(17 \cdot 0 \%)$, and upper limbs $(12 \cdot 8 \%)$. Slightly more injuries occurred in the defensive half of the field of play $(53.2 \%)$ than in the offensive half $(46 \cdot 8 \%)$. More injuries occurred in the second half $(61 \cdot 7 \%)$ than in the first half $(38 \cdot 3 \%)$.

Conclusions-Protective equipment should be introduced to minimise the number and seriousness of injuries in rugby.

(Brf Sports Med 1996;30:61-63)
\end{abstract}

Key terms: injuries; rugby football.

Injuries are inevitable in contact sports, rugby being no exception. ${ }^{12}$ In fact rugby is considered to be one of the dangerous sports. ${ }^{3}$ Specific situations of the game such as the "set scrum", the "rucks", or the "maul" lead to heavy bodily contact and increase the risks of injury. ${ }^{2}{ }^{4}$ Nevertheless, acts of violence could be minimised by strict enforcement of Law 20, which relates to charging, obstruction, foul play, and misconduct. ${ }^{56}$

The injury registration in rugby helps to detect new patterns of injury resulting from changes in style of play, and is of value in identifying means of treatment and rehabilitation, ${ }^{7}$ as indeed it does in other forms of sport. ${ }^{89}$ Many researchers have analysed the occurrence of rugby injuries both in training and competition, classifying them in relation

Table 1 Distribution of injuries per country per match during the Rugby World Cup prequalifying tournament held in Nairobi (Fuly 3rd-10th, 1993)

\begin{tabular}{llllll}
\hline Country & No of injuries & & & \multirow{2}{*}{$\begin{array}{c}\text { Position in } \\
\text { tournament }\end{array}$} \\
\cline { 2 - 5 } & Match 1 & Match 2 & Match 3 & Total (5) & \\
\hline Arabian Gulf & 8 & 6 & 3 & $17(36 \cdot 17)$ & 4 \\
Kenya (Hosts) & 4 & 0 & 3 & $7(14 \cdot 89)$ & 3 \\
Namibia & 2 & 7 & 5 & $14(29 \cdot 79)$ & 1 \\
Zimbabwe & 4 & 3 & 2 & $9(19 \cdot 15)$ & 2 \\
Total & $18(38 \cdot 3 \%)$ & $16(34 \cdot 04 \%)$ & $11(23 \cdot 4 \%)$ & $47(100)$ & \\
\hline
\end{tabular}

to anatomical categorisation, ${ }^{4} 10$ position of play, ${ }^{411-13}$ and time of injury in a game. ${ }^{10}$ The results from these studies are quite variable. No specific pattern of rugby injuries has so far been established.

It is upon this foundation that the present study assessed the nature, anatomical distribution, frequency, timing, and possible causes of injuries that occurred during the Rugby Football World Cup prequalifying matches held in Nairobi, Kenya (July 3-10, 1993).

\section{Methods}

Kenya hosted the Rugby World Cup prequalifying tournament involving the Arabian Gulf, Namibia, Zimbabwe, and Kenya herself. Each of the participating teams played each other during the tournament. A total of six matches was played during days with temperatures varying between 21 and $25^{\circ} \mathrm{C}$ and relative humidity of $40-49 \%$. The pitch conditions were generally dry.

Data were collected by observers with previous experience in the game of field hockey ${ }^{9}$ and volleyball. ${ }^{8}$ The injuries recorded were those that received medical attention with the consent of the match referee. The observers positioned themselves close enough to the touch line for a clear view of the games. Each team played three matches. The results are presented in terms of the first, second, and third matches.

The variables recorded included: type, frequency, and anatomical site of an injury; the part of the field in which it occurred; and the time course of the injury. The diagnosis was confirmed at the end of each game by talking to both the affected player and the head of the medical team. The data were collected using an injury analysis observation sheet and analysed descriptively.

\section{Results}

Forty seven injuries were recorded. This represents an average of about eight injuries per game.

Table 1 shows the distribution of injuries per country per match. In general, the number of injuries decreased from $18(38.3 \%)$ in the first matches to $16(34.9 \%)$ in the second, and finally to $11(23 \cdot 4 \%)$ in the last matches. The only country to which this trend did not appear to apply was Namibia, the eventual winners.

Another interesting observation is that the Arabian Gulf, the losers in this tournament, registered the highest number of injuries $(36 \cdot 2 \%)$, followed by Namibia $(29 \cdot 8 \%)$. There is, however, no clear pattern relating the frequency of injuries to the final standing in the tournament. 
Table 2 Type of injury per match during the Rugby World Cup prequalifying tournament held in Nairobi (fuly 3rd-10th, 1993)

\begin{tabular}{lcccc}
\hline Type of injury & \multicolumn{2}{c}{ Match } & & Total (\%) \\
\cline { 2 - 4 } & 1 & 2 & 3 & \\
\hline Abrasion & - & - & 1 & $1(2 \cdot 13 \%)$ \\
Concussion & 1 & - & - & $1(2 \cdot 13 \%)$ \\
Contusion & 13 & 10 & - & $32(68 \cdot 09 \%)$ \\
Dislocation & - & 1 & 2 & $1(2 \cdot 13 \%)$ \\
Laceration & 1 & 4 & - & $6(12 \cdot 77 \%)$ \\
Nose bleeding & - & 16 & 13 & $1(2 \cdot 13 \%)$ \\
Sprain & 18 & & & $47(100 \cdot 04 \%)$ \\
Total & & & &
\end{tabular}

*Rounding off error

The types of injuries per match are shown in table 2. The majority of the injuries were contusions $(68 \cdot 1 \%)$, followed by lacerations $(12 \cdot 8 \%)$ and sprains $(10 \cdot 6 \%)$.

Table 3 shows the anatomical distribution of the injuries. The lower limbs registered the highest number of injuries $(46 \cdot 8 \%)$ followed by the head $(21 \cdot 3 \%)$, the trunk $(17 \cdot 3 \%)$, the upper limbs $(12 \cdot 8 \%)$, and finally the neck $(2 \cdot 1 \%)$. The thighs alone accounted for $21 \cdot 3 \%$ of all the injuries; $83.0 \%$ affected the muscles, whereas $10.6 \%$ affected the ligaments.

Of the 47 injuries registered, $25(53 \cdot 19 \%)$ occurred in the defensive part of the field, whereas the remaining $22(46 \cdot 81 \%)$ were in the offensive half.

The time course of the injuries shows that only $18(38.3 \%)$ of the injuries occurred during the first half as opposed to $29(61.7 \%)$ in the second half (see the figure). This reflects an increase of $61 \cdot 1 \%$ during the second half. The majority of the injuries occurred between the 61 st and the 70 th minute $(25.5 \%)$, while the least $(6 \cdot 4 \%)$ occurred during the 11 th to the 20th minute. Compared to the same period in the first half (21st to 30th minute), the number of injuries during the 61 st to 70 th minute reflected a $200 \%$ increase.

\section{Discussion}

Most of the studies which have been done to establish the risk probability level for

Table 3 Anatomical distribution of injuries during the Rugby World Cup prequalifying tournament held in Nairobi (Fuly 3rd-10th, 1993)

\begin{tabular}{lrc}
\hline Body part & No & Percent of total \\
\hline Head & & \\
Forehead & 4 & $8 \cdot 5$ \\
Brain & 1 & $2 \cdot 1$ \\
Nose & 1 & $2 \cdot 1$ \\
Mouth & 1 & $2 \cdot 1$ \\
Eye & 2 & $4 \cdot 3$ \\
Ear & 1 & $2 \cdot 1$ \\
Neck & 1 & $2 \cdot 1$ \\
Upper limb & 2 & $4 \cdot 3$ \\
Shoulder & 1 & $2 \cdot 1$ \\
Arm & 2 & $4 \cdot 3$ \\
Wrist joint & 1 & $2 \cdot 1$ \\
Fingers & & $2 \cdot 1$ \\
Trunk & 1 & $6 \cdot 4$ \\
Back & 3 & $2 \cdot 1$ \\
Chest & 1 & $2 \cdot 1$ \\
Abdomen & 1 & $4 \cdot 3$ \\
Waist & 2 & \\
Ribs & & $2 \cdot 1$ \\
Lower limb & 1 & $21 \cdot 3$ \\
Groin & 10 & $8 \cdot 5$ \\
Thigh & 4 & $8 \cdot 5$ \\
Knee & 4 & $6 \cdot 4$ \\
Shin & 3 & $99 \cdot 9 \star$ \\
Ankle & 47 & \\
Total & & \\
\hline
\end{tabular}

${ }^{\star}$ Rounding off error

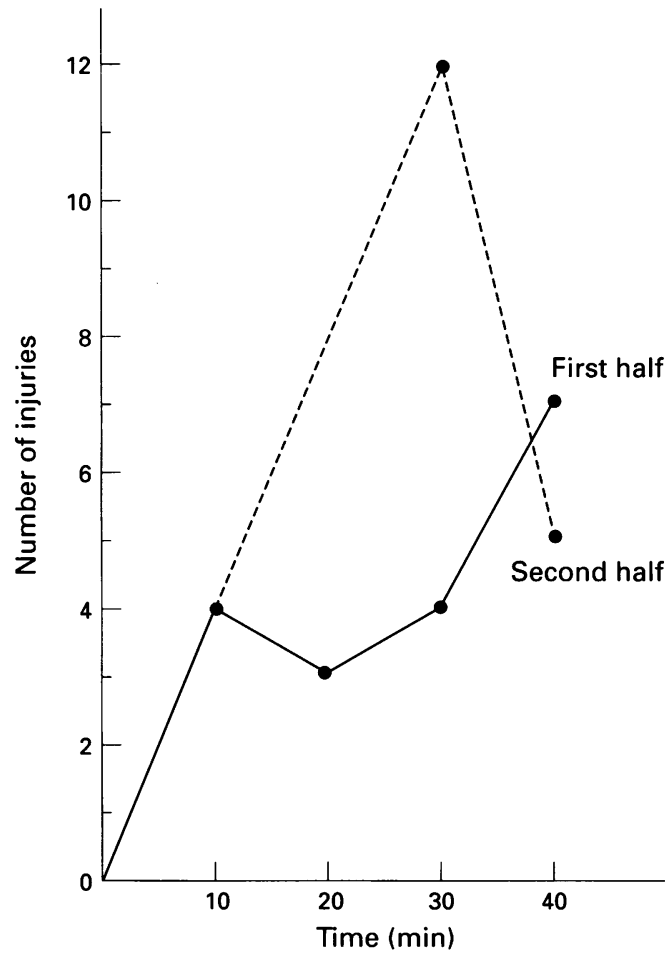

Time course of injuries during the Rugby World Cup prequalifying tournament held in Nairobi, Kenya (fuly 3rd-10th, 1993).

rugby were based on medical records. ${ }^{6}{ }^{11} 13-15$ Although this approach tends to ignore some minor injuries where treatment is not sought, ${ }^{10}$ its modification as used in this study proved useful and convenient. The design of this study differs from all previous ones in rugby as it was prospective rather than retrospective. Therefore, the results obtained are not exactly comparable with those of other studies.

In the tournament under review, the majority of the injuries affected the muscles and the ligaments. This observation is in agreement with other findings in rugby ${ }^{4}$ as well as in hockey, ${ }^{9}$ and soccer. ${ }^{16}$

We noted an average injury rate per game of about eight. This finding compares well with the average of nine by Reilly and Hardiker. ${ }^{10}$

Our observation that the number of injuries decreased as the tournament progressed is difficult to explain on the basis of the data from this study. The number of players remained constant as they had already been registered. We think that the motivation to win must have decreased over time, hence accounting for this trend. However, this needs further investigation.

Most of the injuries in this tournament affected soft tissues. The most serious injury was a concussion. We did not register very serious injuries such as have been recorded elsewhere, for example, fractures ${ }^{5}$ and spinal injuries. ${ }^{6}$

If the field of play is divided into defensive and offensive parts separated by the centre line, then more injuries occurred in the defensive half of the field $(53 \cdot 2 \%)$, although the difference was minimal.

In a study done in Great Britain, more injuries were reported in the second half of the 
game $(55 \cdot 3 \%)$ than in the first half $(44 \cdot 7 \%),{ }^{10}$ while a significantly higher frequency was reported in the third quarter of the game $(32.4 \%)$. Our study was similar, with $38.3 \%$ of the injuries in the first half and $61.7 \%$ in the second. From these two studies, most of the rugby injuries appear to occur between the 50th and the 70th minute. Although the "habitual match routine" has been blamed for this by Reilly and Hardiker, ${ }^{10}$ we suspect fatigue. Fatigue affects the concentration, technique and general coordination. ${ }^{17}$ However, more detailed physiological study of the players within this period would shed more light on this problem and open the way for a preventive approach.

In terms of the anatomical site of injury, previous research findings indicate that the head and face are the frequently injured parts of the body, followed by the lower leg and shoulder. ${ }^{101314}$ Our study showed that the head $(21 \cdot 3 \%)$, the upper leg $(23 \cdot 4 \%)$, and the lower leg $(23.4 \%)$ were affected in near equal proportions. Moreover, the lower limbs $(46 \cdot 8 \%)$ suffered more injuries than the head, neck, and upper limbs combined $(36 \cdot 2 \%)$. This is also true for handball, ${ }^{18}$ hockey, ${ }^{9}$ and soccer. ${ }^{16}$

From our findings and those of previous studies, we believe that it is high time that protective equipment - such as a helmet, face mask, and shoulder pad - was introduced to minimise both the number and severity of injuries in the game of rugby.
1 Doran GA, Allwood C. Towards preventing reinjury in contact sport. $\mathcal{F}$ Sports Med 1984;24:90-3.

2 Hammacher ER. Risks in rugby football. Paper presented at the Second World Congress on Science and Football, May 22-25, Veldhoven, The Netherlands, 1991

3 Blonstein JL. Injuries in sports. Trans Med Soc Lond 1874;90:20-30.

4 Clark DR, Roux C, Noakes TD. A prospective study of the incidence and nature of injuries to all adult rugby players. Paper presented at the second World Congress on Science and Football, May 22-25, Veldhoven, The Netherlands, 1991.

5 Hardiker RJ, Murphy WJ, Shuttleworth JJ. Injuries in rugby union football. In: Reilly T, ed. Sport fitness and sports injuries. London: Faber \& Faber, 1981:1 18-26.

6 Noakes TD, Kew T. A retrospective study of 117 spinal cord injuries in S Africa rugby players. Paper presented at the second World Congress on Science and Football, May 22-25, Veldhoven, The Netherlands, 1991.

7 Van der Neut HW, Hammacher ER, Langenhorst T, Lysen $M$. Injury registration in rugby football. Paper Lysen $M$. Injury registration in rugby football. Paper
presented at the Second World congress on Science and Football, May 22-25, Veldhoven, The Netherlands,

1991

Wekesa $M$. Injuries and illnesses at the 7 th Africa feminine Volleyball club championship. Medicus 1993;12:8-11.

9 Wekesa M, Asembo JM, Njororai WWS. Team Preparation and Medical care of the Kenya National Hockey Team at the Fifth Africa Cup of Nations Championship. $E$ Afr Med F 1993;70:671-7.

10 Reilly T, Hardiker R. Somatotype and injuries in adult student rugby football. $\mathcal{F}$ Sports Med 1981;21:186-91.

11 Durkin TE. A survey of injuries in a first class Rugby Union Football Club from 1972-1976. Br f Sports Med 1977;11:72-4.

12 Roy SP. The nature and frequency of rugby injuries: a pilot study of 300 injuries at Stellenbosch. S Afr Med $\mathcal{F}$ 1974;48:234-7.

13 Van Heerden JJ. An analysis of rugby injuries. $S$ Afr Med f 1976;50:1374-9.

14 Davies JE, Gibson J. Injury in rugby union football. $B M 7$ 1978;ii:1759-61.

15 Michelli LJ, Riseborough EM. The incidence of injuries in rugby football. $\mathcal{F}$ Sports Med 1974;2:93-8.

16 Nielsen AB, Yde J. Epidemiology and traumatology of injuries in soccer. Am $\mathcal{F}$ Sports Med 1989;17:803-7.

7 Hollmann W, Hettinger T. Sportmedizin Arbeits und Trainingsgrundlagen. 3. Aufl. Stuttgart: Schattauer, 1990.

8 Nielsen AB, Yde J. An epidemiologic and traumatologic study of injuries in handball. Int $f$ Sports Med 1988; 9:341-4 